Lecture Notes in Mechanical Engineering 
Lecture Notes in Mechanical Engineering (LNME) publishes the latest developments in Mechanical Engineering - quickly, informally and with high quality. Original research reported in proceedings and post-proceedings represents the core of LNME. Volumes published in LNME embrace all aspects, subfields and new challenges of mechanical engineering. Topics in the series include:

- Engineering Design

- Machinery and Machine Elements

- Mechanical Structures and Stress Analysis

- Automotive Engineering

- Engine Technology

- Aerospace Technology and Astronautics

- Nanotechnology and Microengineering

- Control, Robotics, Mechatronics

- MEMS

- Theoretical and Applied Mechanics

- Dynamical Systems, Control

- Fluid Mechanics

- Engineering Thermodynamics, Heat and Mass Transfer

- Manufacturing

- Precision Engineering, Instrumentation, Measurement

- Materials Engineering

- Tribology and Surface Technology

More information about this series at http://www.springer.com/series/11236 
Magd Abdel Wahab

Editor

\section{Proceedings of the 7th International Conference} on Fracture Fatigue and Wear

FFW 2018, 9-10 July 2018, Ghent University, Belgium

Springer 


\title{
Editor
}

\author{
Magd Abdel Wahab \\ Faculty of Engineering and Architecture \\ Ghent University \\ Ghent, Belgium
}

ISSN 2195-4356

ISSN 2195-4364 (electronic)

Lecture Notes in Mechanical Engineering
ISBN 978-981-13-0410-1
ISBN 978-981-13-0411-8 (eBook)

https://doi.org/10.1007/978-981-13-0411-8

Library of Congress Control Number: 2018947437

(C) Springer Nature Singapore Pte Ltd. 2019

This work is subject to copyright. All rights are reserved by the Publisher, whether the whole or part of the material is concerned, specifically the rights of translation, reprinting, reuse of illustrations, recitation, broadcasting, reproduction on microfilms or in any other physical way, and transmission or information storage and retrieval, electronic adaptation, computer software, or by similar or dissimilar methodology now known or hereafter developed.

The use of general descriptive names, registered names, trademarks, service marks, etc. in this publication does not imply, even in the absence of a specific statement, that such names are exempt from the relevant protective laws and regulations and therefore free for general use.

The publisher, the authors and the editors are safe to assume that the advice and information in this book are believed to be true and accurate at the date of publication. Neither the publisher nor the authors or the editors give a warranty, express or implied, with respect to the material contained herein or for any errors or omissions that may have been made. The publisher remains neutral with regard to jurisdictional claims in published maps and institutional affiliations.

Printed on acid-free paper

This Springer imprint is published by the registered company Springer Nature Singapore Pte Ltd. The registered company address is: 152 Beach Road, \#21-01/04 Gateway East, Singapore 189721, Singapore 


\section{Preface}

This volume contains the Proceedings of the 7th International Conference on Fracture Fatigue and Wear FFW 2018. Fracture Fatigue and Wear 2018 is the 7th FFW conference and is held in the city of Ghent, Belgium, during the period 9-10 July 2018. Previous conferences were celebrated in Jinan (China, 2010), Kitakyushu (Japan, 2013), Kitakyushu (Japan, 2014), Gent (Belgium, 2015), Kitakyushu (Japan, 2016) and Porto (Portugal, 2017).

The overall objective of the conference is to bring together international scientists and engineers in academia and industry in fields related to Fracture Mechanics, Fatigue of Materials, Tribology and Wear of Materials. The conference covers industrial engineering applications of the above topics including theoretical and analytical methods, numerical simulations and experimental techniques. One of the aims of the conference is to promote cooperation between international scientists and engineers from a large number of disciplines, who are involved in research related to Fracture, Fatigue and Wear. The presentations of FFW 2018 are divided into three main sessions, namely (1) Fracture, (2) Fatigue and (3) Wear.

The organising committee is grateful to the keynote speaker, Professor Dr. Eng. Jesús Toribio, Department of Materials Engineering, University of Salamanca (USAL), Spain, for his interesting keynote speech entitled 'Fatigue, Fracture and Wear in Cold-Drawn Pearlitic Steel Wires: Remembering M.C. Escher and J.S. Bach'.

Special thanks go to members of the Scientific Committee of FFW 2018 for reviewing the articles published in this volume and for judging their scientific merits. Based on the comments of reviewers and the scientific merits of the submitted manuscripts, the articles were accepted for publication in the conference proceedings and for presentation at the conference venue. The accepted papers are of a very high scientific quality and contribute to the advancement of knowledge in all research topics relevant to FFW conference. Out of 100 submitted full-length papers, 74 papers are published in the proceedings. 
Finally, the organising committee would like to thank all authors, who have contributed to this volume and to those who have presented their research work at the conference venue in Ghent.

Magd Abdel Wahab Chairman of FFW 2018 


\section{Organisation}

\section{Organising Committee}

\section{Chairman}

Magd Abdel Wahab

Laboratory Soete, Ghent University, Belgium

\section{Co-chairman}

Nao-Aki Noda

Kyushu Institute of Technology, Japan

\section{International Scientific Committee}
S. Abdullah
J. Abenojar
S. Bordas
R. Das
A. Ertas
S. Fouvry
T. Hattori

M. Kchaou

S. Khatir

K. Masuda

T. Miyazaki

K. Oda

R. V. Prakash

T. Qin

F. Rezai-Aria
Universiti Kebangsaan Malaysia, Malaysia

Universidad Carlos III de Madrid, Spain

University of Luxembourg, Luxembourg

University of Auckland, New Zealand

Karabuk University, Turkey

Ecole Centrale de Lyon, France

Shizuoka Institute of Science and Technology, Japan

University of Sfax, Tunisia

Ghent University, Belgium

University of Toyama, Japan

University of Ryukyu, Japan

Oita University, Japan

Indian Institute of Technology, India

China Agricultural University, China

Ecole des Mines d'Albi, France 

A. Rudawska
Phuc Phung Van
M. S. Prabhudev
Y. Sano
J. Song
J. Toribio
C. $\mathrm{Xu}$
T. Yue
C. Zhou

X. Zhuang
Lublin University of Technology, Poland

Ghent University, Belgium

Government Polytechnic, Kalgi, India

Kyushu Institute of Technology, Japan

Ostwestfalen-Lippe University, Germany

University of Salamanca, Spain

China Agricultural University, China

Ghent University, Belgium

Nanjing University of Aeronautics and Astronautics, China

Leibniz Universität Hannover, Germany 


\section{Contents}

\section{Fracture}

Failure Analysis of a Removable Support of a Cockpit Seat

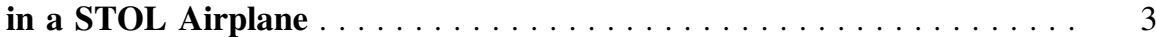

Fernando Delgado

Spot Welding Joint's Fracture Behavior and Fundamental

A. M. Al-Mukhtar, Tareq Rahman, and Qasim Muhammad Doos

Failure and Fracture Analysis of Al-alloy Wheel Rim of a Vehicle

Anagnostis Toulfatzis, Marianna Katsivarda, Andreas Rikos,

Athanasios Vazdirvanidis, and George Pantazopoulos

Key Parameters for Fracture Toughness of Particle/Polymer

Nanocomposites; Sensitivity Analysis via XFEM

Modeling Approach

Khader M. Hamdia and Timon Rabczuk

A Criterion for Crack Initiation at Blunt Notches Based

on the Concept of Local Strength. . . . . . . . . . . . . . . . . . 5

Sergey V. Suknev

Effect of Friction Coefficient and Maximum Contact Pressure

on the Spalling Depth of Gear Teeth Flank

Hasan Heirani and Khalil Farhangdoost

Transient Analysis of Multiple Interface Cracks in Two Bonded

Elastic and Piezoelectric Layers .

Mojtaba Ayatollahi, Soroor Varasteh, and Amir Hossein Fartash

A Study on the Constitutive Equation Effects in the Fracture Initiation of AA5450 Sheets .

Shahram A. Dizaji, Haluk Darendeliler, and Bilgin Kaftanoğlu 
Predicting the Failure Type of Liquid Hydrocarbon Pipeline Using

Fuzzy Expert System

Zhichao Cui, Shengli Liu, and Yongtu Liang

Simulation of Loading Rate Effects on Dynamic Brittle Failure of Concrete Structures Using a Two-Scale Damage Model

M. K. Atiezo, W. Chen, and C. Dascalu

Deformation Behavior and Fracture of Al-CuZr Nano-Laminates:

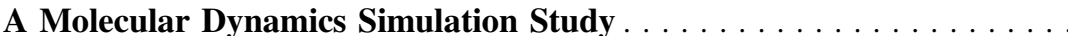

Pradeep Gupta and Natraj Yedla

Model of Damaged Medium for Describing Fatigue Fracture

of Materials and Structures

I. A. Volkov, L. A. Igumnov, S. Yu. Litvinchuk, I. V. Vorobtsov, and M. V. Grigoryev

Modeling of Fatigue Fracture of Coatings in Multi-cycle

Friction Contact .

Elena Torskaya

Research and Modeling of Stress-Strain State and Fracture Strength of Triplexes at Temperatures 293-213 K

Mykola Pidgurskyi, Yuri Rudyak, and Ivan Pidgurskyi

Influence of Low Temperature on Mechanical Properties of Carbon

Steel P110 Estimated by Means of Small Punch Test.

Malwina Stępniewska, Barbara Romelczyk-Baishya, Tomasz Brynk,

Maciej Giżyński, and Zbigniew Pakieła

Crack Propagation in Various Double Cantilever Beam

Geometric Configurations .

Lucie Malíková and Hana Šimonová

Lateral Indentation and Impact Analyses on Curved

Composite Shells

Donato Di Vito, Tuomas Pärnänen, Jarno Jokinen, Olli Orell, and Mikko Kanerva

Structured Learning-Based Sinusoidal Modelling for Gear Diagnosis and Prognosis

Mengqiu Tao, Wenyi Wang, Zhihong Man, Zhenwei Cao, Hai Le Vu, Jinchuan Zheng, and Antonio Cricenti

Singular Stress Field of Interfacial Small Crack in Orthotropic

Bonded Plate

Kazuhiro Oda, Shunya Yasada, and Noriko Tsutsumi 
Comparative Research on Calculation Methods of Stress Intensity

Factors and Crack Propagation Criterion

Chun Qing, Zhang Chengwen, and Jia Xiaohu

Crack Identification Using eXtended IsoGeometric Analysis

and Particle Swarm Optimization

Samir Khatir, Magd Abdel Wahab, Brahim Benaissa, and Mario Köppen

\section{Fatigue}

PWR Fatigue Testing at SCK $\cdot \mathrm{CEN}$ in the Framework

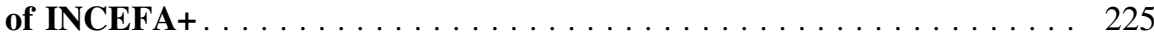

Marc Vankeerberghen, Pierre Marmy, and Luc Bens

The Effect of Technological and Structural Factors on the Strength of Polyethylene Adhesive Joints

Anna Rudawska, Magd Abdel Wahab, Dalibor Barta,

and Saugirdas Pukalskas

Compression of Strain Load History Using Holder Exponents

of Continuous Wavelet Transform

C. H. Chin, S. Abdullah, S. S. K. Singh, D. Schramm, A. K. Ariffin, and N. N. M. Nasir

Structural Optimization for the Gusset Plate in the Boom Structure of Concrete Pump Truck

Seungoh Han and Jiwoon Kwon

Failure Analysis of Prematurely Failed Hip Joint Implant Inside

the Femur Bone

S. P. Butee and Kaustubh Kambale

Comparative Study of Defect-Based and Plastic Damage-Based

Approaches for Fatigue Lifetime Calculation of Selective

Laser-Melted AlSi12.

M. Awd, S. Siddique, R. Hajavifard, and F. Walther

Fatigue Damage of Waterwall Tubes in a 1000 MW USC Boiler

Chang Che, Gong Qian, Xisheng Yang, and Xiang Liu

Fatigue of Steels Used in the Manufacture of Components for Heavy

Load Vehicles

J. J. Ramírez-Natera, C. A. Salazar, A. Z. Rodríguez,

F. A. Pérez-González, J. H. Ramírez-Ramírez, I. García,

N. F. Garza-Montes-de-Oca, and R. Colás 
Specimen Thickness Effects on Front Edge Shape of Fatigue Crack in Al7075-T6 Alloy

Kenichi Masuda, Sotomi Ishihara, Arthur J. McEvily, and Masaki Okane

Finite Lifetime Estimation of Mechanical Assemblies Subjected

to Fretting Fatigue Loading

C. V. Teuchou Kouanga, J. D. Jones, I. Revill, A. Wormald, D. Nowell,

R. S. DwyerJoyce, J. A. Araújo, and L. Susmel

Probabilistic Modeling of Coating Delamination

Ilya I. Kudish, Harutyun A. Amirjanyan, and Vahram N. Hakobyan

Failure of Giant Wheel Ride at an Amusement Park .

Muhammad Rizwan Shad and Faiz ul Hasan

Thermal-Mechanical Fatigue Analysis of a Main Steam Isolation

Valve of a Boiling Water Reactor-5 . . . . . . . . . . . . . . . . . . . . . . . . . 379

I. Álvarez-Loya, J. A. Santillán-Gómez, C. J. Huesca-Damián,

L. H. Hernández Gómez, J. A. Beltrán-Fernández, and P. Ruiz-López

Influence of Soft Particle Peening Treatment on Fatigue Strength of Aluminum Alloy A5052

Koichiro Nambu and Masahiro Okumiya

Fatigue Life Calculation of Load-Adapted Hybrid Angular Contact

Ball Bearings

Florian Pape, Timm Coors, Yang Wang, and Gerhard Poll

The Influence of Hydrogen on Fatigue Fracture in Mooring

Chain Steel .

Xiaoying Cheng and Xiaoyan Zhang

Monitoring Micro-damage Evolution in Structural Steel S355 Using Speckle Interferometry .

Konrad Ritter and Klaus Thiele

On an Extension of the Fatemi and Socie Equation for Rolling Contact in Rolling Bearings .

Paul Sauvage, Georg Jacobs, Christopher Sous, Bernd Lüneburg,

Daniel Becker, and Klaus Pantke

Durability of Steel Joints with Ductile Adhesive Subjected

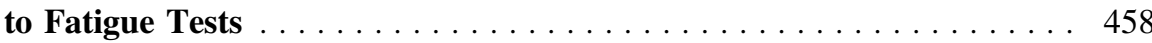

B. Enciso, E. Paz, C. Trujillo, J. Abenojar, and M. A. Martínez

Effect of an Adhesive Bonding on the Fatigue Life of Advanced High

Strength Steel Spot-Welds

S. J. Chu, T. K. Jeong, and K. J. Hwang 
Fatigue Life Predictions for L-Shaped Cracks . . . . . . . . . . . . . . . . . . 480

Silvia Corbani, Luiz Fernando Martha, Jaime Tupiassú Pinho de Castro, and Bruce Carter

Modelling of Short Crack Arrest and Fatigue Propagation

Using Non-local Fracture Criteria

A. Nosikov

Critical Analysis of Randomly Rough Surfaces for Contact Mechanics Through Statistical Simulation . . . . . . . . . . . . . . . . . . . . . 500

Miguel Ángel Ramírez, Carlos Gabriel Figueroa, Víctor Hugo Jacobo, Armando Ortiz, and Rafael Schouwenaars

Panel Test for New Developed Airbus A321 ACF Overwing Door and Surrounding Structure

Sven Berssin

Strain Rate Concentration Factor for Round and Flat

Test Specimens

Nao-Aki Noda, Rei Takaki, Yunong Shen, Akane Inoue, Yoshikazu Sano, and Yasushi Takase

A Comparison Between Critical-Plane and Stress-Invariant Approaches for the Prediction of Fretting Fatigue Crack Nucleation

N. A. Bhatti, K. Pereira, and M. Abdel Wahab

Effect of Short Crack Behavior on the Propagation Life Prediction for a Fretting Cylindrical Pad Configuration

K. Pereira and M. A. Wahab

Simulation of Cyclic Deformation Behavior of Ferritic P92 Steel Based on Unified Viscoplastic Model

Xiaowei Wang, Wei Zhang, Jianming Gong, and Magd Abdel Wahab

Fatigue Life Analysis of Un-repaired and Repaired Metallic Substrate Using FRANC2D 558

S. Pitta, J. I. Rojas, D. Crespo, and M. Abdel Wahab

\section{Wear}

Effect of Cryosoaking Period on Soft Tempering Temperature and Wear Mechanism in AISI H11 Tool Steel

N. B. Dhokey, P. Lalge, A. Rajankar, K. Bawane, and R. Mahajan

Dry Wear Behavior of Basalt/Carbon-Reinforced Epoxy Composite

by Taguchi Method

Y. Şahin and F. Şahin 
Wear Property of Epoxy Reinforced with Carbon Using a Response Surface Methodology . . . . . . . . . . . . . . . . . . . . . . . . . . . 591 Y. Şahin, M. Yankaş, A. M. Tokdede, and P. De Baets

Microabrasive Wear of Titanium Chrome Plated 602 Castillo-Sánchez Martín, Velázquez-Vázquez María, Vite-Torres Manuel, and Gallardo-Hernández Ezequiel

Experimental Investigate of the Wear and Friction Performance Considering Effects of Surface Topography and Lubricant .

Xianghui Meng and Youbai Xie

Experimental Simulation and Analysis of Die Casting Mould Wear . . 621 Zvonimir Dadić, Dražen Živković, Nikša Čatipović, and Ivo Marinić-Kragić

Structure and Properties of the New Antifriction Composite Materials for High-Temperature Friction Units . . . . . . . . . . . . . . . . . . . . 628 Krzysztof Jamroziak and Tetiana Roik

Comprehension of Thermomechanical Phenomena and Material Behavior During High Speed Contact

M. Thévenot, V. Wagner, J.-Y. Paris, G. Dessein, J. Denape, A. Brunet, and T. Chantrait

An Investigation into the Early Life Cycle Wear-Induced Failure of an All-Terrain Vehicle Ball Joint Cotter Pin

Alex Roberts and Keith Rogers

In-manufacture Running-in of Engine Components by Using the Triboconditioning ${ }^{\circledR}$ Process

Boris Zhmud

Wear Behavior of $\mathrm{ZrO}_{2}$ Particle Reinforced (Fe,Ni)

Matrix Composite.

Neera Singh, Om Parkash, and Devendra Kumar

Nanoscale Wear of Carbon Overcoat Subjected to Laser Heating in an Inert Gas Environment .

Norio Tagawa, Hiroshi Tani, Shinji Koganezawa, and Renguo Lu

Wear Simulation Method for Mechanical Seals Under Mixed

Lubrication Using Flow Factors

Di Liu, Shaoping Wang, Chao Zhang, and Mileta Tomovic

Boride Coating on Titanium Alloys as Biomaterial in Wear and Fretting Applications

V. Peretti, A. Bari, S. Ferraris, G. Gautier, B. Stella, A. M. Tortora, and S. Spriano 
Wear Behavior of ZTA Reinforced Iron Matrix Composites . . . . . . . . 732

Lei Fan, Huahui Chen, Haicun Li, Daoren Fu, and Haiping Hong

Friction and Wear of Mouthguard Material with a Laser-Textured

Surface in Reciprocating Sliding Motion

Tomoharu Akagaki, Kazuki Sasaki, Tadateru Kurosawa,

and Hukukai Kaku

Effect of Prior Ratcheting Deformation on Low Cycle Fatigue

Behaviour of AISI 4340 Steel

Krishna Dutta and K. Divya Bharathi

Finite Element Model in Abrasion Analysis for Single-Asperity

Scratch Test 768

P. Wechsuwanmanee, J. Lian, J. Sukumaran, Á. Kalácska,

H. Ben Hamouda, P. De Baets, and S. Münstermann

Analysis of the Fretting Wear Phenomenon on the Surface Coatings of Form-Wound Coil

M. Vite-Torres, F. P. Espino-Cortés, T. Asiaín-Olivares,

J. Zaragoza-Granados, and E. A. Gallardo-Hernández

Tribological and Mechanical Properties of Polyester Based

Composites with SiC Particles

J. Abenojar, S. López de Armentia, P. Gálvez, and M. A. Martínez

Numerical Calculation of Local Adhesive Wear in Machine Elements

Under Boundary Lubrication Considering the Surface Roughness . . . 796

J. T. Terwey, S. Berninger, G. Burghardt, G. Jacobs, and G. Poll

Numerical Investigation and Optimization of Loosening Behavior of Wheel Nuts for Passenger Cars . . . . . . . . . . . . . . . . . . . . . . . 808

Ali Kara and Emre Cubuklusu

Optimization of Rigidity of Aluminum Alloy Wheels

Onur Kocaturk, Fatih Yasin Elagoz, and Ali Kara 